Article

\title{
Optimization of Base Catalyzed Ethanolysis of Vegetable Oils in Microreactors Using Design of Experiments
}

\author{
Ekaterina Borovinskaya ${ }^{1,2, *}$, Eva Ritter ${ }^{1}$ and Wladimir Reschetilowski ${ }^{1,2}$ \\ 1 Technische Universität Dresden, 01062 Dresden, Germany; Eva_Maria.Ritter@mailbox.tu-dresden.de (E.R.); \\ wladimir.reschetilowski@tu-dresden.de (W.R.) \\ 2 Saint-Petersburg State Institute of Technology (Technical University), 190013 St.-Petersburg, Russia \\ * Correspondence: Ekaterina.borovinskaya@tu-dresden.de
}

Received: 31 December 2019; Accepted: 18 February 2020; Published: 29 February 2020

\begin{abstract}
The base-catalyzed ethanolysis of soybean oil and waste cooking oil (WCO) was investigated in two types of continuous reactors (microreactor and T-mixer) and in a batch reactor. Flow rate, ethanol/oil ratio and concentration of catalyst were varied according to the design of experiments in continuous reaction systems. Regression analysis was carried out concerning the obtained product yields. Based on this analysis optimal conditions in different reactors types with soybean oil, fresh and WCO were determined. While the increased flow rate was unfavorable in the MX-mixer, it contributed to a great positive impact in the T-mixer system at flow rates higher than $2.2 \mathrm{~mL} / \mathrm{min}$. The soybean oil provides a slightly lower yield maximum (96.7\%) than the fresh cooking oil (97.9\%) and the waste cooking oil (97.5\%). Therefore, the mix of vegetable oils in the cooking oil is more suitable for ethanolysis reaction than the soybean oil.
\end{abstract}

Keywords: microreactors; ethanolysis; soybean oil; waste cooking oil; design of experiments

\section{Introduction}

Biodiesel is a promising alternative to diesel, which is gained from fossil resources. Biodiesel from vegetable oils provides lower carbon dioxide and greenhouse gas emission compared to fossil fuels and, therefore, has a smaller environmental impact [1]. Nowadays, biodiesel is industrially produced through transesterification of high fatty acids (triacylglycerols), which are mostly gained from soybean, rapeseed and palm oil [2], and methanol or ethanol as aliphatic alcohol in a base-catalyzed transesterification reaction. As catalyst $\mathrm{NaOH}$ or $\mathrm{KOH}$ can be used. Since methanol is obtained from mineral oil, ethanol can be produced in the fermentation process from biomass. The food industry is deprived if using soybean oil or other cooking oils for biodiesel production. Applying waste cooking oil or non-edible oils like algae oil for the ethanolysis provides environmentally friendlier biodiesel [3]. The suitability of the oil for the reaction depends on the number of triacylglycerols [2]. The reaction mechanism includes three stages. In the first stage (1), triacylglycerol $(\mathrm{T})$ is converted into diacylglycerol (D) while one equivalent of fatty acid ester (E) with ethanol is formed. In the second stage (2) another equivalent of alcohol (R-OH) reacts with $\mathrm{D}$ and forms monoacylglycerol (M) and glycerol $(G)$ in the last step (3). With each of the reversible steps, one equivalent of $\mathrm{R}-\mathrm{OH}$ is needed and one equivalent of fatty acid ethyl (FAEE) ester is formed.

$$
\begin{aligned}
& \mathrm{T}+\mathrm{ROH} \rightleftharpoons \mathrm{D}+\mathrm{E} \\
& \mathrm{D}+\mathrm{ROH} \rightleftharpoons \mathrm{M}+\mathrm{E}
\end{aligned}
$$




$$
\mathrm{M}+\mathrm{ROH} \rightleftharpoons \mathrm{G}+\mathrm{E}
$$

Previous studies have shown that it is possible to conduct the transesterification reaction in continuously operated microreactors [4]. Microreactors provide advantages like higher controllability, safer dealing with toxic chemicals and easy scale-up by numbering-up. Moreover, microreactors make available micromixing of the reactants, which can lead to higher yields [5]. Oil and alcohol phase (with the catalyst) are involved in the ethanolysis reaction leading to mass transfer limitations [2]. Due to micromixing, a higher phase boundary interface can be obtained because of a higher surface-to-volume-ratio of the reactants and short diffusion distances [6]. Methanolysis or ethanolysis reaction was investigated in several microreactors [5,7-9]. Wen et al. [7] used zig-zag microreactors and observed a reaction yield of $97.3 \%$ at $56^{\circ} \mathrm{C}$, methanol-oil-ratio of $6: 1,1.6 \mathrm{wt}$.- $\% \mathrm{KOH}$ and $18 \mathrm{~s}$ residence time. Schwarz et al. [8] worked with a T-mixer and different microreactors, and obtained a maximum yield of $93.8 \%$ in a split-and-recombine micromixer at $50{ }^{\circ} \mathrm{C}$, molar ethanol/oil ratio of $6: 1$, $1 \mathrm{wt} . \mathrm{\%} \mathrm{KOH}$ and $11.3 \mathrm{~min}$ residence time. Sun et al. [9] showed that at $1 \mathrm{wt} . \mathrm{\%} \mathrm{KOH}$ catalyst, molar methanol/oil ratio of $6: 1$ and $60{ }^{\circ} \mathrm{C}$ reaction temperature the alcoholysis of rapeseed and cottonseed oil in a capillary microreactor with an inner diameter of $0.25 \mathrm{~mm}$ led to maximum yields of $99.4 \%$ FAEE after a reaction time of $5.89 \mathrm{~min}$. The mixing of the reactants was performed in a separate container before the mixture was pumped through the capillary reactor. The authors found out that further increasing the catalyst concentration, the molar ethanol/oil ratio, the temperature or the reaction time was counterproductive for the investigated reactor system.

The aim of this paper is to determine optimal reaction conditions for base-catalyzed transesterification of different oil types and in different reactor systems using design of experiments.

\section{Materials and Methods}

\subsection{Materials}

Soybean oil was obtained from "Sojola". The fresh cooking oil and waste cooking oil ("Optima Halbflüssiges Frittierfett" from the company Walter Rau Lebensmittelwerke $\mathrm{GmbH}$ ) was provided by a local canteen. Ethanol (99.9\%, VWR Chemicals GmbH, 01127 Dresden, Germany), potassium hydroxide (85\%, Sigma-Aldrich Co., LLC., St. Louis, MO, USA), sodium hydroxide (99\%, Sigma-Aldrich Co., LLC., St. Louis, MO, USA) and hydrochloric acid (37\%, Merck KGaA, 64293 Darmstadt, Germany) were acquired from commercial sources at the highest grade.

\subsection{Methods}

The experiments were carried out in a T-reactor, a microreactor (LTF-MX) and in a batch reactor. The experimental setup for continuous experiments can be seen in Figure 1. The oil and the alcohol-catalyst-solution were provided by two syringe pumps (P1, P2) which were connected to the mixer (C1) with a Teflon capillary tube (S1, S2). The dwell section V (C2) was connected to the respective mixer with a Teflon capillary tube (S3). Teflon capillary tubes (S4) of certain lengths were attached at the end of the dwell section, which then led directly to the sample collecting container (B1).

The entire reactor system was heated to $50{ }^{\circ} \mathrm{C}$, using a water bath (B2, W1). The pumps were provided by New Era Pump Systems Inc., the glass syringes by Braun.

In the T-reactor the two fluids meet each other horizontally in the mixer $\mathrm{C} 1$ at a certain flow rate. In the microreactor setup, the reaction mixture is separated and recombined several times in the micromixer $\mathrm{C} 1$ and fed into dwell section $\mathrm{V}(\mathrm{C} 2)$. After the reaction, the products streamed in $0.75 \mathrm{wt} .-\%$ aqueous $\mathrm{HCl}$ to quench the reaction. The structures of the MX-mixer (a), the T-mixer (b) and the dwell section V (c) are shown in Figure 2. A full factorial design was used for each reactor to determine the optimal conditions for the reaction. The results were then applied to experiments in the batch mode. 


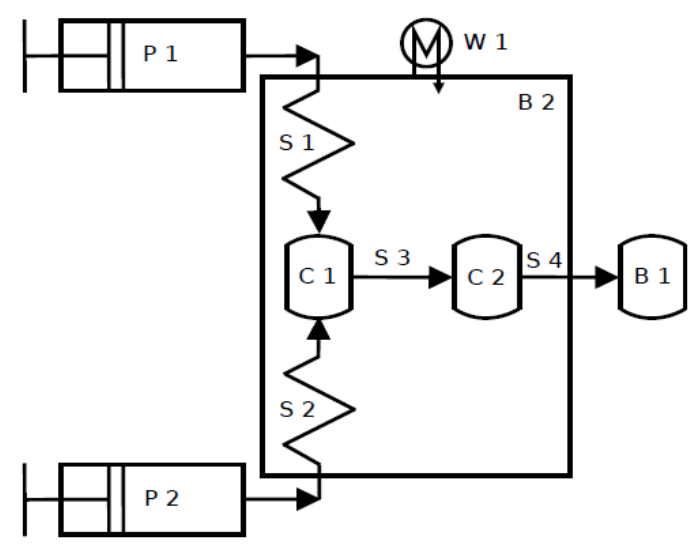

Figure 1. Experimental setup for continuous flow experiments.

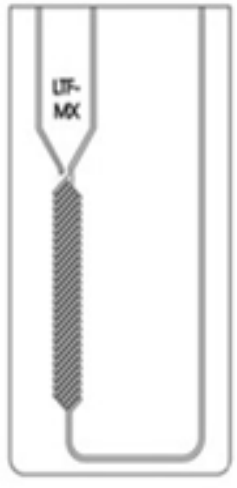

a

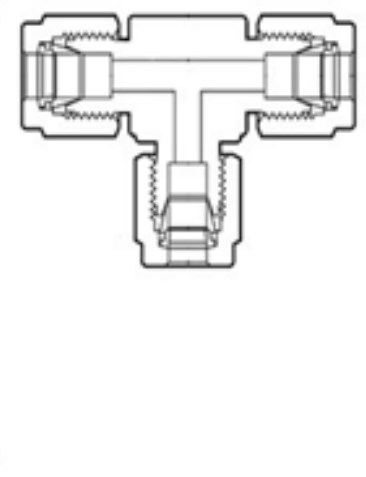

b

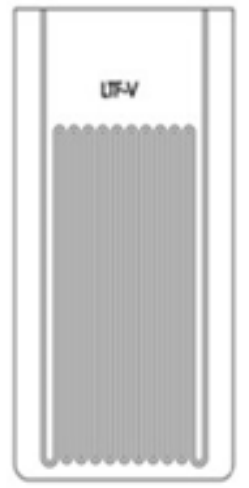

C

Figure 2. Structure of mixers and dwell section: (a) MX-mixer; (b) T-mixer; (c) dwell section V.

The waste cooking oil was filtered from coarse contaminations. The batch process was performed by adding $20 \mathrm{~mL}$ of a solution of $1.46 \mathrm{~g} \mathrm{KOH}$ in $50 \mathrm{~mL} \mathrm{EtOH}$ to $49.62 \mathrm{~g}(53.76 \mathrm{~mL})$ oil provided in a $100 \mathrm{~mL}$ heated glass vessel under magnetically stirring with $1000 \mathrm{rpm}$. Samples of the product gained in the batch mode were taken at $40 \mathrm{~s}$ and 1,2, 5 and $8 \mathrm{~min}$ and quenched in $0.75 \mathrm{wt} . \%$ aqueous $\mathrm{HCl}$. The analysis of the products was performed by high-performance liquid chromatography (HPLC). The percentage amount of the obtained FAEE, the remaining oil (T) and the byproducts ( $D, M$; summarized as NP) was determined by means of calibration.

\subsection{Design of Experiments}

The parameters for the continuous reaction systems (MX-V and T-V) were varied according to a full factorial design, which allows a subsequent regression analysis. According to a $2^{3}$ experimental design, eight experimental points and three middle points were provided. The molar ethanol/oil ratio $\left(\mathrm{x}_{1}\right)$, the volume flow rate $\left(\mathrm{x}_{2}\right)$ and the amount of the $\mathrm{KOH}$ catalyst $\left(\mathrm{x}_{3}\right)$ were chosen for the investigation, while the time on stream $(4 \mathrm{~min})$ and the temperature $\left(50^{\circ} \mathrm{C}\right)$ were kept constant. Based on previous works the initial parameter values were selected $[8,10]$. The experimental plan for the full factorial design can be seen in Table 1 .

The volume flow rate in the system with the T-reactor was varied between 1.79 and $3.99 \mathrm{~mL} / \mathrm{min}$, while all other parameters were the same as with the MX-mixer (Table 1). The experimental plan was examined with respect to the adequacy of the model approach according to Fischer [11] and the significance of the investigated parameters. Based on the obtained experimental results, a linear regression equation, which shows the parameter impact on the reaction yield of FAEE, can be formulated:

$$
\mathrm{y}=\mathrm{f}\left(\mathrm{x}_{\mathrm{k}}\right)=\mathrm{b}_{0}+\mathrm{b}_{1} \cdot \mathrm{x}_{1}+\mathrm{b}_{2} \cdot \mathrm{x}_{2}+\mathrm{b}_{3} \cdot \mathrm{x}_{3}
$$


For better operation, the parameters $x_{k}$ were transformed into dimensionless values $\vartheta_{\mathrm{k}}$ which assumed value +1 or -1 and formed the plan matrix of the experimental design. A normalized, linear regression approach can be set up from the plan matrix:

$$
y=f\left(\vartheta_{k}\right)=a_{0}+a_{1} \cdot \vartheta_{1}+a_{2} \cdot \vartheta_{2}+a_{3} \cdot \vartheta_{3}
$$

The regression equation includes experimental errors as well as errors introduced due to the model choice and is to be confirmed by statistical tests. For this purpose, the model dispersion $D_{m}$ was determined from the sum of squared residuals (SSR) and the degrees of freedom of the model $F G_{1}$. The sum of squared errors (SSE) was calculated using the mean value of the experimental values in the middle point of the plan matrix. Taking into account the degrees of freedom of the experiment $F G_{2}$, the experimental dispersion $D_{E}$ was calculated from the SSE. A quotient of the model and experimental dispersion provides information about the adequacy of the regression approach [12]. It has to be smaller than the value of the F-distribution $\left(F_{\alpha}, F G_{1}, F G_{2}\right)$ at a significance level of the test $\alpha=5 \%$.

Table 1. Full factorial design for the continuous reaction system with MX-mixer.

\begin{tabular}{ccc}
\hline $\mathbf{n}_{\text {EtOH }} / \mathbf{n}_{\text {oil }}$ & $\dot{V}[\mathbf{m L} / \mathbf{m i n}]$ & wt.- $\mathbf{K O H}$ \\
\hline $8: 1$ & 2.6 & 0.860 \\
$6: 1$ & 1.5 & 0.645 \\
$10: 1$ & 1.5 & 0.645 \\
$6: 1$ & 3.7 & 0.645 \\
$10: 1$ & 3.7 & 0.645 \\
$6: 1$ & 1.5 & 1.075 \\
$10: 1$ & 1.5 & 1.075 \\
$6: 1$ & 3.7 & 1.075 \\
$10: 1$ & 3.7 & 1.075 \\
\hline
\end{tabular}

Based on the model adequacy, the dimensionless coefficients of the regression equation were considered for their significance. The dimensionless coefficients $\left(\vartheta_{1}\right.$ ethanol-oil-ratio, $\vartheta_{2}$ flow rate, $\vartheta$ mass percentage of catalyst) have to exceed a value $\Delta \mathrm{a}_{k}=t_{\alpha, F G} \sqrt{s_{a}^{2}}$. with $t_{\alpha, F G}$-value for the Student's t-distribution and $s_{a}^{2}$-dispersion of model coefficients. The significance levels $\Delta \mathrm{a}_{\mathrm{k}}=6.3$ for the system with T-mixer and 3.3 for the system with the MX-mixer.

The new experimental parameters for the optimization were determined via dimensionless, significant coefficients of the regression equation. According to the Box-Wilson method, the objective function is optimized in the direction of the highest increase [12]. For this purpose, a new search step size was defined for the parameter with the largest coefficient of the regression equation. The new step size was the double starting step size for the most significant parameters of the experimental plan. The new values for the parameters with significant coefficients were calculated and optimal values were applied to the experiments.

\section{Results and Discussion}

The FAEE yields in the continuous reaction system at different flow rates and molar ratios are listed in Table 2 and displayed in Figure 3. Figure 3 shows that the MX-mixer provides higher yields at lower flow rates and otherwise similar parameters compared to the T-mixer. An opposite effect can be observed at higher flow rates. This could be explained by diverging flow dynamics [8]. Because of the MX-mixer geometry, the efficient mixing of components at lower flow rates can be observed. In the T-mixer, the higher flow rate is required for good mixing. 
Table 2. Fatty acid ethyl ester (FAEE) yields for MX- and T-mixer at $\mathrm{KOH}=0.645$ wt.-\%.

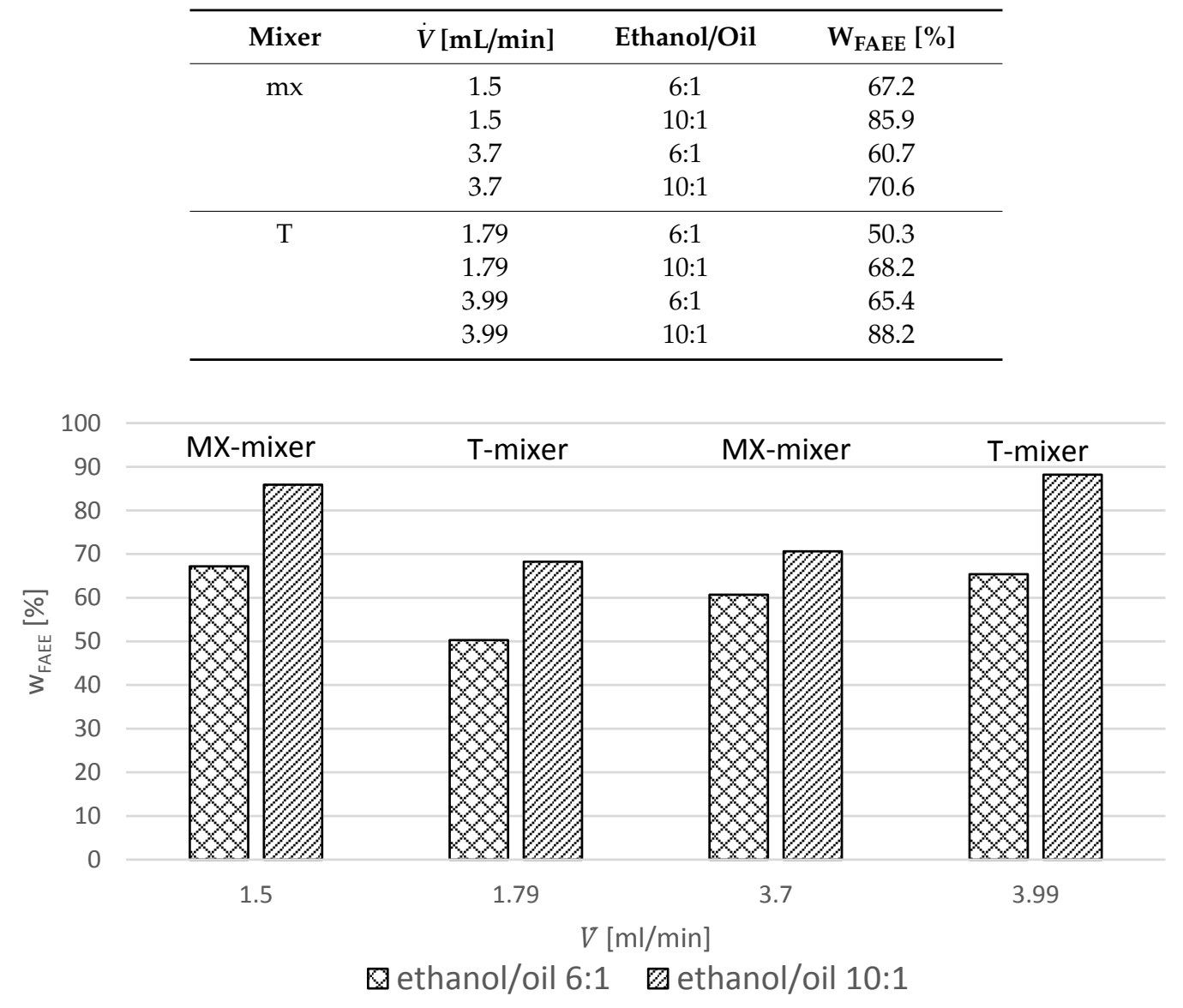

Figure 3. FAEE yields in $\mathrm{MX}$ - and T-mixer at $\mathrm{KOH}=0.645$ wt.- $\%$.

In order to consider the significance of the parameters, the dimensionless coefficients (ethanol/oil ratio, flow rate and the mass percentage of catalyst) have to exceed the value for the Student's t-distribution (Table 3) [11].

Table 3. Dimensionless coefficients of parameters and significance levels $\Delta \mathrm{a}_{\mathrm{k}}$.

\begin{tabular}{ccc}
\hline Dimensionless Coefficient & MX-Mixer & T-Mixer \\
\hline$\Delta \mathrm{ak}$ & 3.3 & 6.3 \\
$\mathrm{a}_{1}$ & 6.3 & 8.3 \\
$\mathrm{a}_{2}$ & -3.0 & 10.8 \\
$\mathrm{a}_{3}$ & 2.8 & 0.3 \\
\hline
\end{tabular}

The regression analysis of the reaction in the MX-mixer shows that only the ethanol/oil ratio $\left(a_{1}\right)$ has a significant impact on the yield of FAEE. The flow rate $\left(a_{2}\right)$ has a negative sign and is not significant. In the T-mixer only flow rate $\left(a_{2}\right)$ and ethanol/oil ratio $\left(a_{1}\right)$ are significant. The variation of the flow rate in this system provides a higher impact on the yield than the molar ethanol/oil ratio. This result confirms that the flow rate has a great influence on the blending of the components in the T-mixer. The amount of the catalyst $\left(a_{3}\right)$ shows no significant impact on the experiment in both reactor systems. The calculated dimension specific coefficients for the MX-and the T-mixer are presented in Table 4.

In Equations (6) and (7) the significant coefficients for both investigated reactor systems (with MX-mixer and T-mixer) are presented.

$$
\mathrm{y}=\mathrm{f}\left(\mathrm{x}_{\mathrm{k}}\right)=44.9+3.1 \cdot \mathrm{x}_{1}
$$




$$
\left.\mathrm{y}=\mathrm{f}\left(\mathrm{x}_{\mathrm{k}}\right)=7.0+4.1 \cdot \mathrm{x}_{1}+9.8 \cdot \mathrm{x}_{2}\right)
$$

Regression equations depending on the ethanol/oil ratio at a constant flow rate $\mathrm{x}_{2}=2.89 \mathrm{~mL} / \mathrm{min}$ in the MX-V and T-V reactor system can be formulated (Figure 4). It shows that raising the ethanol/oil ratio in the reactor system with T-mixer would lead to higher yields of FAEE ( $w_{\text {FAEE }}[\%]$ ) than in the reactor system with MX-mixer. At ethanol/oil ratios under 9.5:1 the MX-V reactor system is more efficient than the T-V reactor system, while higher ethanol/oil ratio provides a slightly higher efficiency in the case of T-mixer.

Table 4. Dimension specific coefficients for MX- and T-mixer.

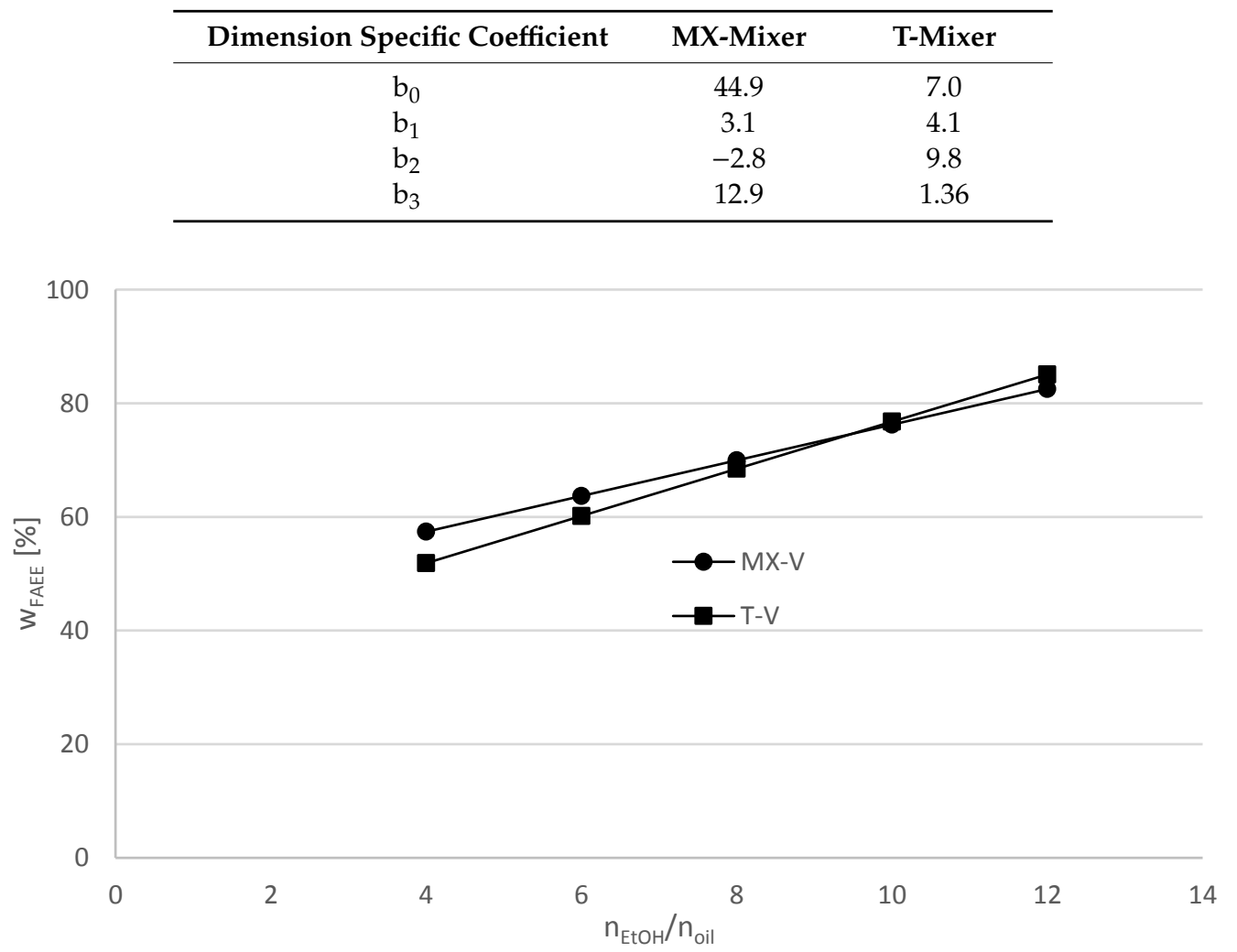

Figure 4. Graphical presentation of the regression equations for different reactor systems as a dependency of the molar ethanol/oil ratio.

The influence of the flow rate on the FAEE yield in the T-reactor system at a constant molar ethanol/oil ratio $=10: 1$ is shown in Figure 5. A high positive impact of the flow rate in the T-mixer, and a reverse phenomenon in the MX-mixer can be observed. Due to a better blending in the T-mixer, the T-reactor system is more suitable for flow rates higher than $2.2 \mathrm{~mL} / \mathrm{min}$ compared to the MX-V reactor system.

The optimization was conducted in both continuous systems according to the Box-Wilson method [12]. New values for the parameters were calculated based on the regression coefficient with the greatest impact on the respective reactor system. The optimized parameters are presented in Table 5 with the middle points (line 1 in Table 1) of the plan matrix.

In both reactor systems, the optimized parameters provided an increase of the FAEE yield. Using the MX-mixer, the mass fraction of FAEE could be raised from $68.1 \%$ to $84.9 \%$. With the T-mixer the yield of FAEE could be increased from $61.8 \%$ to $90.8 \%$. Increased flow rate had a great positive impact on reaction yields in the system with the T-mixer.

The optimized parameters were applied to the experiments in the batch reactor and compared for soybean oil, original cooking and waste cooking oil (Table 6). 


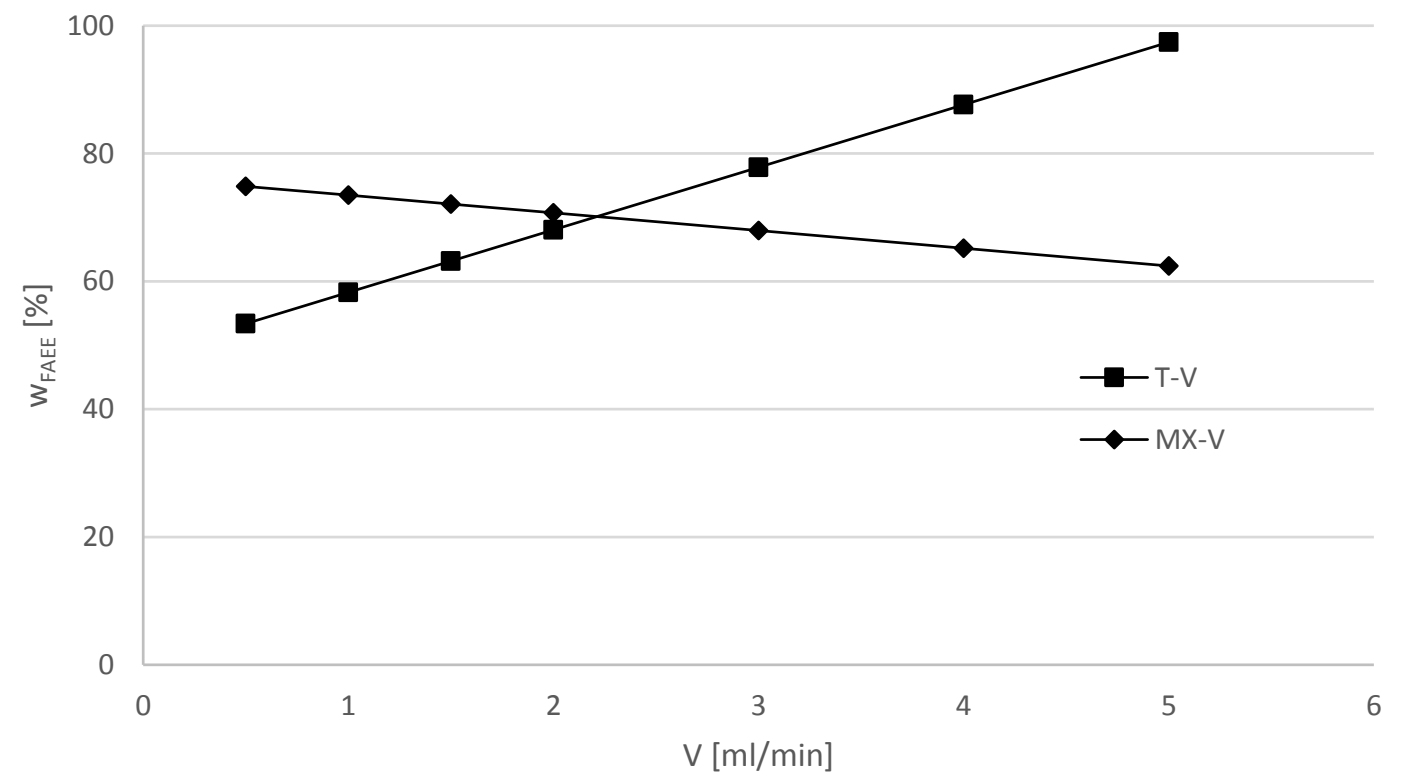

Figure 5. Graphical presentation of the regression equations for different reactor systems as a dependency of the flow rate.

Table 5. Middle points and optimized parameter values for investigated reaction systems.

\begin{tabular}{ccccc}
\hline & \multicolumn{2}{c}{ MX-Mixer } & \multicolumn{2}{c}{ T-Mixer } \\
\cline { 2 - 5 } & Middle Points & Optimized Values & Middle Points & Optimized Values \\
\hline \multirow{2}{*}{$\mathrm{nEtOH} /$ noil } & $8: 1$ & $12: 1$ & $8: 1$ & $11: 1$ \\
& 2.6 & 2.6 & 2.89 & 5.09 \\
$V$ & 0.86 & 0.86 & 0.86 & 0.86 \\
\hline wFEE[ml/min] [\%] & 68.1 & 84.9 & 61.8 & \multirow{2}{*}{90.8} \\
wt.-[\%] KOH & & & & \\
\hline
\end{tabular}

Table 6. Experimental parameters for the ethanolysis at $50{ }^{\circ} \mathrm{C}$ and $\mathrm{KOH}=0.86 \mathrm{wt} .-\mathrm{\%}$ in a batch reactor.

\begin{tabular}{cllllll}
\hline Oil & \multicolumn{2}{c}{ Soybean } & \multicolumn{2}{c}{ Cooking } & \multicolumn{2}{c}{ Waste } \\
\hline nEtOH/noil & $11: 1$ & $12: 1$ & $11: 1$ & $12: 1$ & $11: 1$ & $12: 1$ \\
max. wFAEE [\%] & 94.8 & 96.7 & 96.6 & 97.9 & 82.1 & 97.5 \\
\hline
\end{tabular}

All experimental results are shown in Table 7. The FAEE yield with soybean oil at ethanol-oil-ratio $=11: 1$ and 12:1 in the batch reactor is illustrated in Figure 6. For a molar ethanol/oil ratio = 11:1, a maximum yield $=94.8 \%$ FAEE was detected after a reaction time of $8 \mathrm{~min}$. The product yield remained nearly constant after a reaction time of $5 \mathrm{~min}$, indicating that the reaction was practically finished. At the ethanol/oil ratio = 12:1 the maximum FAEE yield of 96.7\% was detected after $8 \mathrm{~min}$. The product yield of the experiment with the molar ethanol/oil ratio $=11: 1$ is exceeded, showing that a higher excess of ethanol has a positive effect on the reaction.

Figure 7 shows the reaction results of the experiment with the original cooking oil at molar ethanol/oil ratios $=11: 1$ and 12:1. The maximum yield $=96.6 \%$ for the ethanol-oil-ratio $=11: 1$ was detected after $8 \mathrm{~min}$. It can be assumed that this value could be further increased by a longer reaction time. The highest yield in the reaction with the molar ethanol/oil ratio $=12: 1$ could be detected at $8.5 \mathrm{~min}$. A higher amount of ethanol leads to higher yields indicating a need for high alcohol excess. 
Table 7. FAEE yields ( $\left.\mathrm{w}_{\mathrm{FAEE}}[\%]\right)$ in a batch reactor by ethanolysis reaction of soybean oil, original cooking and waste cooking oil.

\begin{tabular}{cccccccc}
\hline & $\mathbf{n}_{\text {EtOH }} / \mathbf{n}_{\text {oil }}$ & $\begin{array}{c}\text { Soybean } \\
\text { Oil }\end{array}$ & $\begin{array}{c}\text { Original } \\
\text { Cooking Oil }\end{array}$ & $\begin{array}{c}\text { Waste } \\
\text { Cooking Oil }\end{array}$ & $\begin{array}{c}\text { Soybean } \\
\text { Oil }\end{array}$ & $\begin{array}{c}\text { Original } \\
\text { Cooking Oil }\end{array}$ & $\begin{array}{c}\text { Waste } \\
\text { Cooking Oil }\end{array}$ \\
\cline { 3 - 8 } & $\mathbf{1 1 : 1}$ & $\mathbf{1 1 : 1}$ & $\mathbf{1 1 : 1}$ & $\mathbf{1 2 : 1}$ & $\mathbf{1 2 : 1}$ & $\mathbf{1 2 : 1}$ \\
\hline 0.7 & 66.8 & 78.1 & 73.1 & 64.0 & 68.8 & 56.6 \\
1 & 70.5 & 80.7 & 74.8 & 71.1 & 73.9 & 83.0 \\
2 & 75.6 & 85.2 & 77.8 & 78.8 & 87.4 & 89.9 \\
5 & 94.3 & 93.1 & 80.1 & 85.9 & 96.9 & 93.3 \\
8 & 94.8 & 96.6 & 82.1 & 96.7 & 97.9 & 97.5 \\
\hline
\end{tabular}

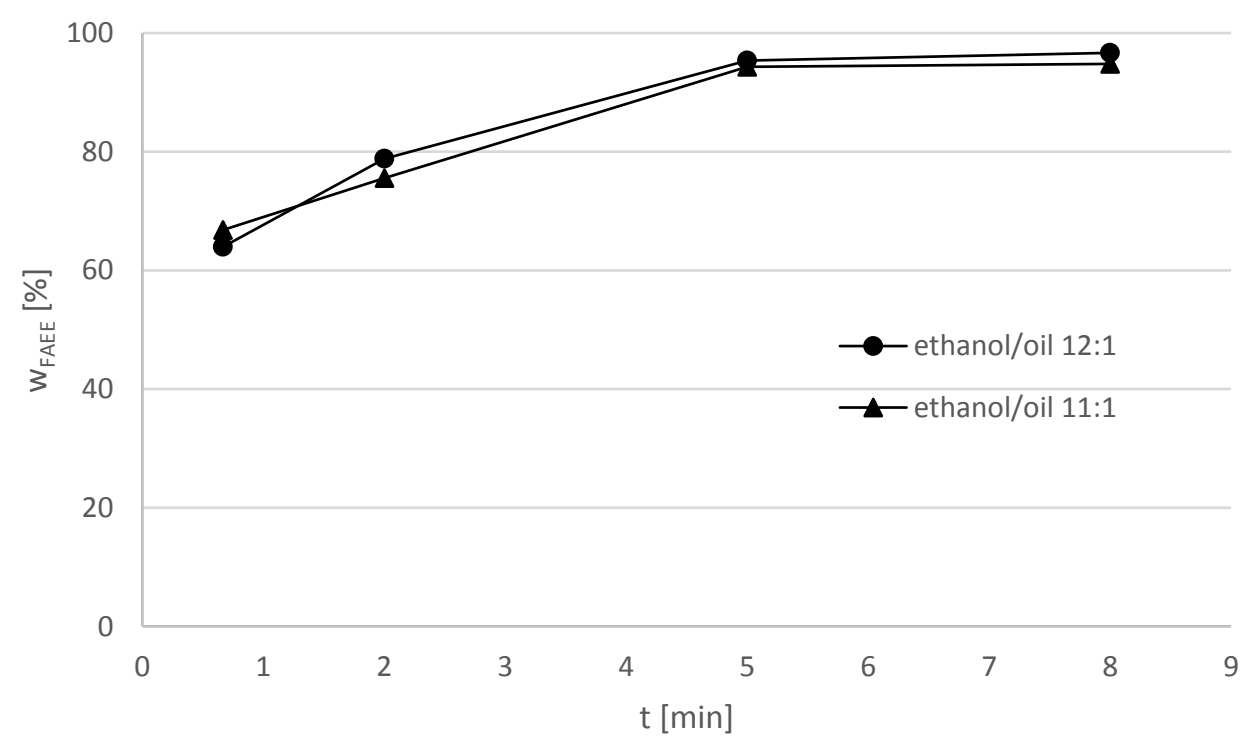

Figure 6. FAEE yields in the batch reactor at molar ethanol/oil ratios =11:1 and 12:1 with soybean oil.

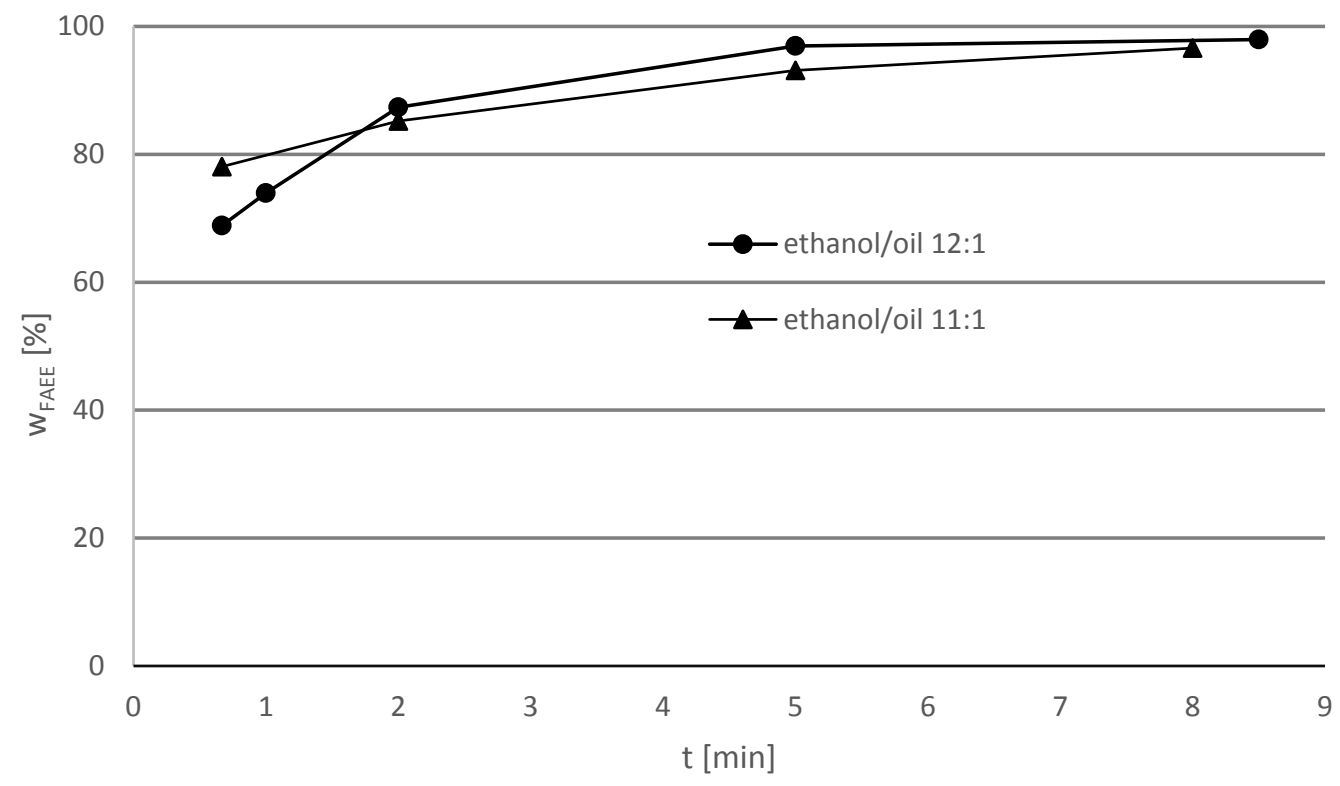

Figure 7. FAEE yields in the batch reactor at molar ethanol/oil ratios $=11: 1$ and $12: 1$ with original cooking oil.

The same conclusion can be provided from the experimental results obtained with waste cooking oil (Figure 8). The effect of ethanol excess on the FAEE yield is very significant. The product analysis 
for the molar ethanol/oil ratio $=11: 1$ showed that the amount of byproduct remained relatively high throughout the reaction. This could be partially provided due to contamination of the waste cooking oil with food debris, since only coarse particles could be filtered before usage. It is also known that used cooking or frying oil has a higher acid value which means it contains a higher amount of free fatty acids (FFA) than cooking oil [13]. It decreases the biodiesel yield of the reaction because FFAs can be saponified by the catalyst [14]. An excess amount of alcohol would counter this phenomenon by shifting the equilibrium of the saponification to the reactant's side and thereby favoring the alcoholysis of the FFA.

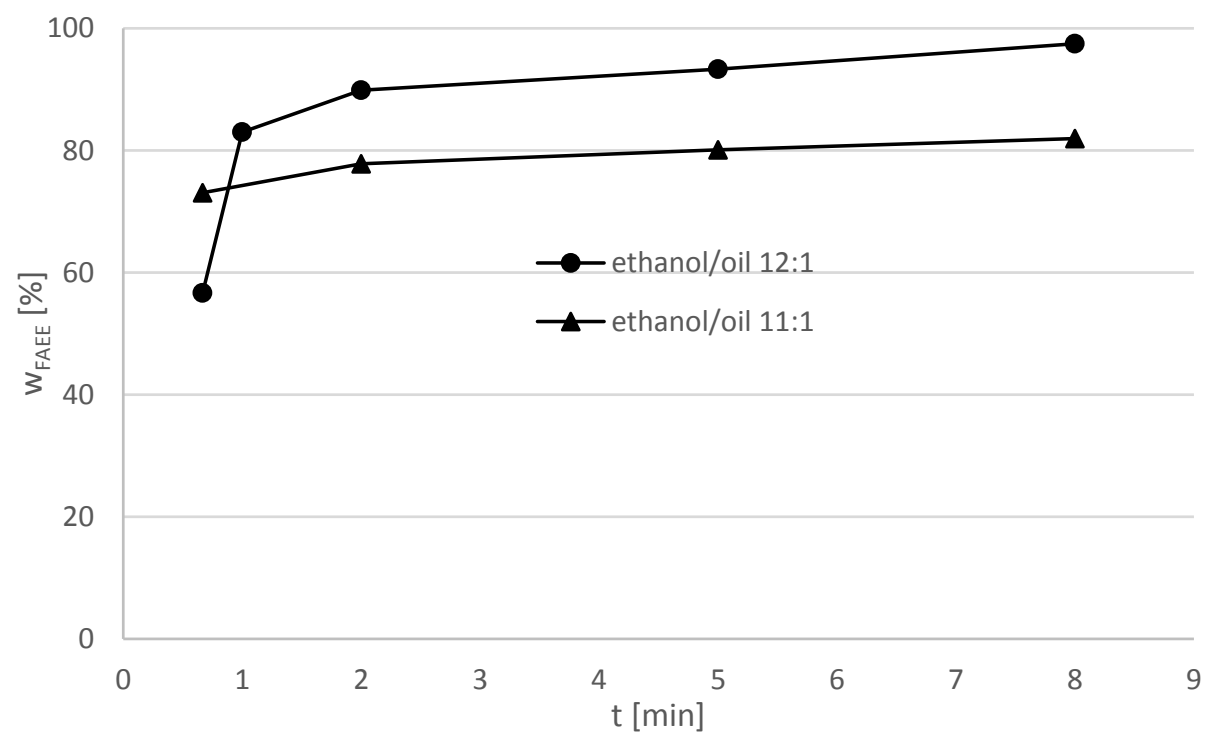

Figure 8. FAEE yields in the batch reactor at ethanol-oil-ratios $=11: 1$ and 12:1 with waste cooking oil.

Figures 9 and 10 show the direct comparison of FAEE yields for different types of oils.

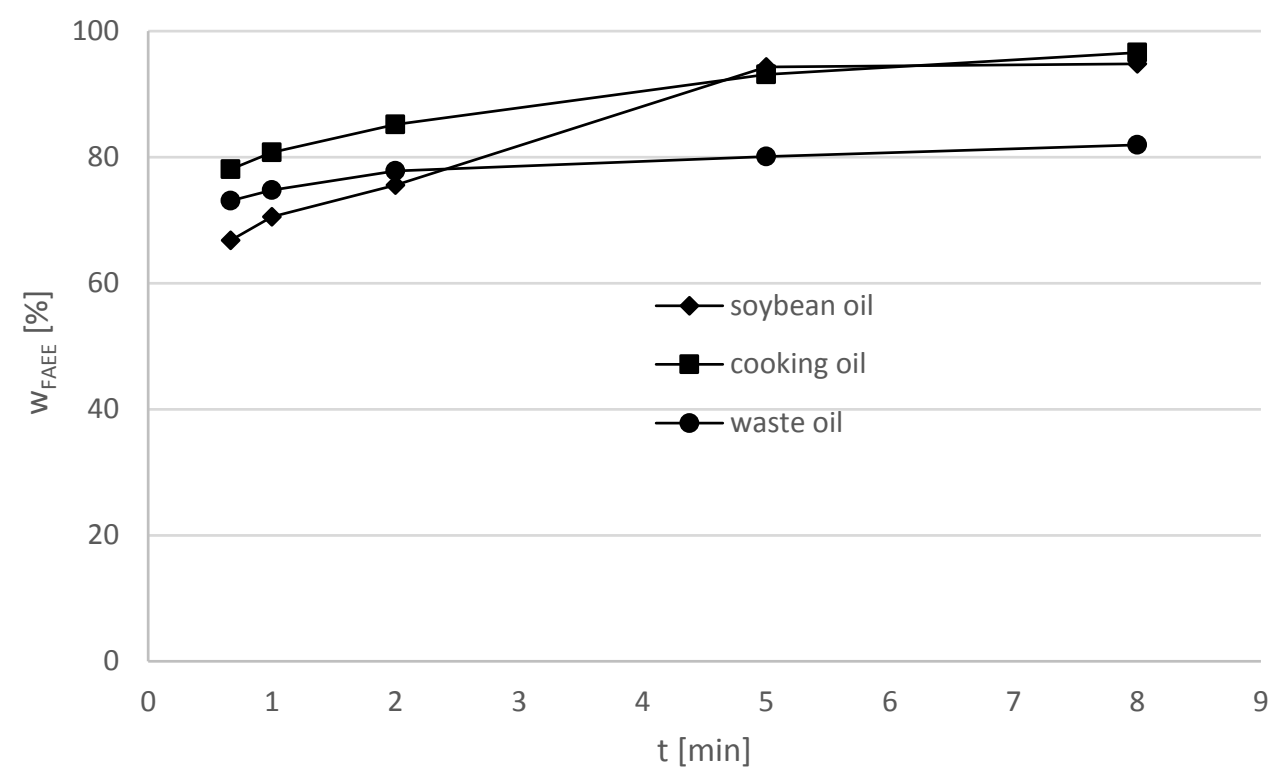

Figure 9. FAEE yields for soybean oil, original cooking oil and waste cooking oil in a batch reactor at molar ethanol/oil ratio 11:1.

At a molar ethanol/oil ratio $=11: 1$ the original cooking oil provided a higher yield $(96.6 \%)$ than the soybean oil (94.8\%) at 8 min reaction time. Since the exact composition of the cooking oil is unknown it can only be assumed that the vegetable oils contained hold properties more appropriate for the 
transesterification. Using the waste cooking oil, the product yield was distinctively lower and a FAEE yield of $82.0 \%$ was obtained.

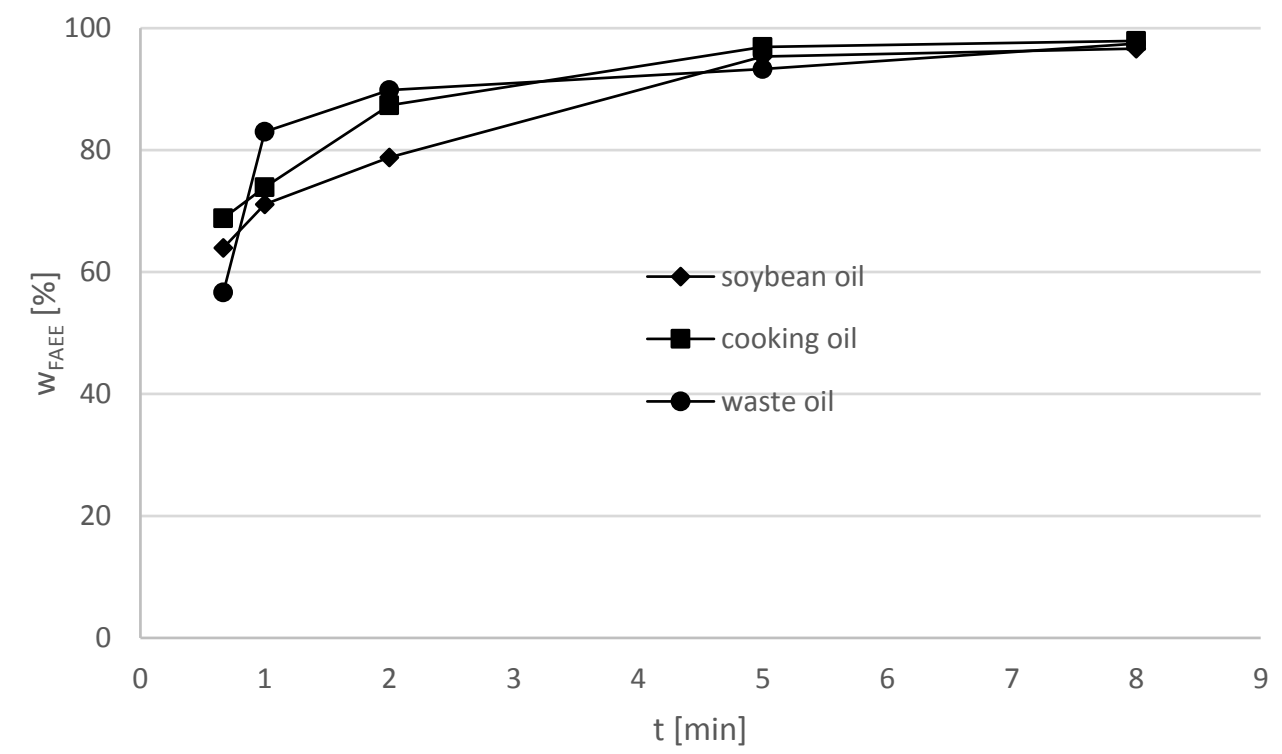

Figure 10. FAEE yields for soybean oil, original cooking oil and waste cooking oil in a batch reactor at a molar ethanol/oil ratio 12:1.

Figure 10 shows the experimental results at a molar ethanol/oil ratio of 12:1. The soybean oil provides slightly lower maximum yields $(96.7 \%)$ of FAEE than the original cooking oil $(97.9 \%)$ and the waste cooking oil (97.5\%), indicating that the mix of vegetable oils in the cooking oil is more suitable for alcoholysis than soybean oil.

The increase of yields achieved can be described in a logarithmical function for the batch reactor experiments with soybean oil. By determining equations for this increase, the yields of the reactions after $4 \mathrm{~min}$ can be interpolated and then compared to the results in MX-and T-mixer reactor systems with soybean oil at the respectively optimal conditions from Table 5 (Table 8).

Table 8. Comparison of FAEE yields for the batch reactor and $\mathrm{MX}-\mathrm{V}$ and $\mathrm{T}-\mathrm{V}$ reactor system (interpolated) experiments with soybean oil after $4 \mathrm{~min}$.

\begin{tabular}{ccc}
\hline $\mathbf{n}_{\text {EtOH }} / \mathbf{n}_{\text {oil }}$ & $\mathbf{1 1 : 1}$ & $\mathbf{1 2 : 1}$ \\
\hline $\mathrm{T}-\mathrm{V}$ & 90.8 & - \\
$\mathrm{MX}-\mathrm{V}$ & - & 84.9 \\
Batch & 87.7 & 86.4 \\
\hline
\end{tabular}

Applying the calculated optimal reaction parameters for the MX-V reactor system to the experiment in the batch reactor leads to a higher product yield of $86.4 \%$. The product yield of $90.8 \%$ at optimal reaction conditions in the T-V reactor system could not be exceeded in the batch mode under otherwise equal reaction conditions.

In previous works, the maximum product yield of $93.8 \%$ FAEE using soybean oil in the MX-V reactor system was obtained at a reaction time of $11.3 \mathrm{~min}$ and molar ethanol/oil ratio $=6: 1$, the catalyst concentration $1 \mathrm{wt} . \mathrm{\%}$, the flow rate $0.565 \mathrm{~mL} / \mathrm{min}$ and the temperature $50{ }^{\circ} \mathrm{C}$ [14]. Interpolating the product yield of the reaction from a logarithmic equation depending on reaction time suggests the FAEE yield $=84.9 \%$ after $4 \mathrm{~min}$. This result was reproduced using the same reactor system and reaction temperature but at a lower catalyst concentration of $0.86 \mathrm{wt} .-\%$, higher molar ethanol/oil ratio of 12:1 and the higher flow rate $=2.6 \mathrm{~mL} / \mathrm{min}$. Using the T-V reactor system, the interpolated product yield of $43.9 \%$ obtained in [15] with a flow rate of $0.535 \mathrm{~mL} / \mathrm{min}$ and otherwise equal experimental conditions in 
the MX-V reactor system could be exceeded using a higher flow rate $=5.09 \mathrm{~mL} / \mathrm{min}$, a molar ethanol/oil ratio $=11: 1$ and catalyst concentration $=0.86 \mathrm{wt} . \%$, leading to $90.8 \%$ FAEE. These results show very clearly that an excess of alcohol has a positive influence on the reaction yield.

A good mixing of the reactants in the T-mixer is generated at a higher flow rate, which is crucial for obtaining high FAEE yields. This principle doesn't apply to the MX-mixer. Leung and Guo [13] found out that increasing the stirring speed in methanolysis experiments (producing fatty acid methyl ethers, FAME) conducted in batch mode had a positive effect on the product yield. Authors conducted experiments with used frying oil (UFO) and neat canola oil and obtained a maximum FAME yield $=88.8$ wt. $-\%$ at optimal reaction conditions $\left(1.1 \mathrm{wt} .-\%\right.$ catalyst $(\mathrm{NaOH}), 60^{\circ} \mathrm{C}$ reaction temperature, $15 \mathrm{~min}$ reaction time and a molar methanol/oil ratio of 7:1), while the optimal conditions for the neat canola oil $\left(1 \mathrm{wt} .-\% \mathrm{NaOH}, 45^{\circ} \mathrm{C}, 15 \mathrm{~min}\right.$, methanol/oil ratio 6:1) provided a maximum FAME yield = 93.5\%. Other researchers [16] performed ethanolysis experiments with waste cottonseed oil in batch mode and found that at a molar ethanol/oil ratio of $12: 1,65{ }^{\circ} \mathrm{C}$ and $2.5 \mathrm{~h}$ reaction time, $98 \%$ FAEE were obtained, using 5 wt. $\%$ of a 3 wt.- $\%$ Li/CaO catalyst.

Not only the reaction parameters but also the type and oil composition have a high impact on the FAEE yield. Previous works $[15,17,18]$, as well as the experiments carried out in this work, showed that the product yield for the alcoholysis strongly depends on the acid value (amount of FFA) of the oil, due to occurring saponification reaction.

Since the suitability of different oils for the alcoholysis could only be accurately determined by performing the reactions under otherwise completely equal conditions, a statement on this cannot be made. However, in the past, vegetable oils like sunflower, soybean, palm or rapeseed oil proved to be reasonable feedstocks [13]. But the economic aspect of the production is a very important one, which implies that the oil yield of the crop should be as high as possible. Ghazali et al. [19] mentioned in their review on the effects of different biodiesel feedstocks on the engine that about $70-80 \%$ of the total production cost account for the cost of the raw materials. In view of this, they stated that palm oil is the most suitable edible vegetable oil for biodiesel production, while Jatropha oil is the best non-edible one for this purpose. By optimizing the reaction conditions, the production costs could be further decreased due to possible energy-saving methods.

The efficiency of base-catalyzed transesterification, primarily conducted in batch reactors, can be substantially increased by a continuous process in microstructured reactors. Due to the much higher area/volume ratios, faster reaction rates and a faster mass and heat transfer in the base-catalyzed ethanolysis of waste cooking oils can be achieved in microreactors. Other enhancements are shorter diffusion distances and reduced residence times [15].

The techno-economic implication of the atmospheric and subcritical heterogeneous transesterification [20] and results from present work were compared. The authors report the time of reaction about $1-3 \mathrm{~h}$ at $70{ }^{\circ} \mathrm{C}$. The reaction in microreactors needs several minutes at $50{ }^{\circ} \mathrm{C}$ providing lower costs and higher capacities for the industrial application.

\section{Conclusions}

Base catalyzed transesterification of oils with alcohols is an established batch process for biodiesel production. The application of a continuous flow process in microreactors leads to process intensification. The ethanolysis of soybean oil was studied in microreactors using Design of Experiments (DoE).

Experimental results show that the enhancement of the flow rate has a very-high positive impact on the FAEE yield in the system with T-mixer, while in the MX-V reactor system a longer residence time is important. In the system MX-mixer, the $\mathrm{w}_{\mathrm{FAEE}}$ could be raised from $68.1 \%$ to $84.9 \%$ after optimization procedure. High flow rates have a negative impact on the yield of the desired product in the MX-V reactor system. While the increased flow rate was counterproductive in the MX-mixer, it had a great positive impact on the reaction yields in the system with the T-mixer. The $\mathrm{w}_{\mathrm{FAEE}}$ in the system with T-mixer could be increased from $61.8 \%$ to $90.8 \%$. Due to better blending in the T-mixer, the T-V 
reactor system is more suitable than the MX-V reactor system for flow rates higher than $2.2 \mathrm{~mL} / \mathrm{min}$. The batch reactor experiments lead to the highest product yields, though at an extended reaction time.

Usage of waste cooking oil provides reasonable product yields in the discontinuously conducted experiments at a molar ethanol/oil ratio $=12: 1$. The soybean oil provides slightly lower maximum FAEE yields $=96.7 \%$ than the original cooking oil $97.9 \%$ and the waste cooking oil $(97.5 \%)$. This indicates that the mix of vegetable oils in the cooking oil is more suitable for alcoholysis reaction than the soybean oil.

It is important to apply these reaction parameters to a continuous mode process, particularly with waste oil and ethanol, because it is important to desist from edible oils as feedstock. As mentioned above, the continuous experiments were characterized by higher controllability, safer dealing with toxic chemicals and easy up-scaling.

Author Contributions: Conceptualization, E.B. and W.R.; methodology, E.B.; validation, E.B., E.R. and W.R.; formal analysis, E.R.; investigation, E.R.; resources, W.R.; data curation, E.B.; writing-original draft preparation, E.R.; writing-review and editing, E.B.; visualization, E.R.; supervision, W.R.; project administration, W.R. All authors have read and agreed to the published version of the manuscript.

Funding: This research received no external funding.

Acknowledgments: Open Access Funding by the Publication Fund of the TU Dresden.

Conflicts of Interest: The authors declare no conflict of interest.

\section{References}

1. Hill, J.; Nelson, E.; Tilman, D.; Polesky, S.; Tiffany, D. Environmental, economic, and energetic costs and benefits of biodiesel and ethanol biofuels. Proc. Natl. Acad. Sci. USA 2006, 103, 11206. [CrossRef] [PubMed]

2. Stamenkovic, O.S.; Velickovic, A.V.; Veljkovic, V.B. The production of biodiesel from vegetable oils by ethanolysis: Current state and perspectives. Fuel 2011, 90, 3141-3155. [CrossRef]

3. Gui, M.M.; Lee, K.T.; Bhatia, S. Feasibility of edible oil vs. non-edible oil vs. waste edible oil as biodiesel feedstock. Energy 2008, 33, 1646-1653. [CrossRef]

4. Santacesaria, E.; Martinez Vicente, G.; Di Serio, M.; Tesser, R. Main technologies in biodiesel production: State of the art and future challenges. Catal. Today 2012, 195, 2-13. [CrossRef]

5. Qiu, Z.; Zhao, L.; Weatherley, L. Process intensification technologies in continuous biodiesel production. Chem. Eng. Process. 2010, 49, 323-330. [CrossRef]

6. Jähnisch, K.; Hessel, V.; Löwe, H. Chemistry in microstructured reactors. Angew. Chem. Int. Ed. 2004, 43, 406. [CrossRef] [PubMed]

7. Wen, Z.; Yu, X.; Tu, S.; Yan, J.; Dahlquist, E. Intensification of biodiesel synthesis using zigzag micro-channel reactors. Bioresour. Technol. 2009, 100, 3054-3060. [CrossRef] [PubMed]

8. Schwarz, S.; Borovinskaya, E.; Reschetilowski, W. Base catalyzed ethanolysis of soybean oil in microreactors: Experiments and kinetic modeling. Chem. Eng. Sci. 2013, 104, 610-618. [CrossRef]

9. Sun, J.; Ju, J.; Ji, L.; Zhang, L.; Xu, N. Synthesis of Biodiesel in Capillary Microreactors. Ind. Eng. Chem. Res. 2008, 47, 1398-1403. [CrossRef]

10. Borovinskaya, E.S.; Reschetilowski, W. Perspectives of heterogeneous process intensification in microreactors. Russ. J. Gen. Chem. 2019, 82, 2108-2115. [CrossRef]

11. Leiner, B. Einführung in die Statistik; Walter de Gruyter GmbH \& Co KG: Berlin, Germany, 2004.

12. Bandemer, H.; Bellmann, A. Statistische Versuchsplanung; Auflage, Teubner Verlag: Stuttgart, Germany, 1994.

13. Leung, D.Y.C.; Guo, Y. Transesterification of neat aud used frying oil: Optinimazion for biodiesel production. Fuel Process. Technol. 2006, 87, 883-890. [CrossRef]

14. Fennema, O.R. Food Chemistry, 3rd ed.; Marcel Dekker Inc.: New York, NY, USA, 1996.

15. Borovinskaya, E.S.; Sabaditsch, D.; Reschetilowski, W. Base-Catalyzed Ethanolysis of Waste Cooking Oil in a Micro/Millireactor System: Flow and Reaction Analysis. Chem. Eng. Technol. 2019, 42, 495-505. [CrossRef]

16. Kaur, M.; Ali, A. Ethanolysis of waste cottonseed oil over lithium impregnated calcium oxide: Kinetics and reusability studies. Renew. Energy 2014, 63, 272-279. [CrossRef]

17. Liu, K. Preparation of fatty acid methyl esters for gas-chromatographic analysis of lipids in biological materials. J. Am. Oil Soc. Chem. 1994, 71, 1179-1187. [CrossRef] 
18. Zhang, Y.; Dub, M.A.; McLean, D.D.; Kates, M. Biodiesel production from waste cooking oil: 1. Process design and technological assessment. Bioresour. Technol. 2003, 89, 1-16. [CrossRef]

19. Ghazali, W.N.M.W.; Mamat, R.; Masjuki, H.H.; Najafi, G. Effects of biodiesel from different feedstocks on engine performance and emissions: A review. Renew. Sustain. Energy Rev. 2015, 51, 585-602. [CrossRef]

20. Labib, T.M.; Hawash, S.I.; El-Khatib, K.M.; Sharaky, A.M.; El Diwani, G.I.; Abdel Kader, E. Kinetic study and techno-economic indicators for base catalyzed transesterification of Jatropha oil. Renew. Egypt. J. Pet. 2013, 22, 9-16. [CrossRef]

(C) 2020 by the authors. Licensee MDPI, Basel, Switzerland. This article is an open access article distributed under the terms and conditions of the Creative Commons Attribution (CC BY) license (http://creativecommons.org/licenses/by/4.0/). 